\title{
Survival of Didymella bryoniae in Buried Watermelon Vines in South Carolina
}

\author{
Anthony P. Keinath, Associate Professor, Department of Plant Pathology and Physiology, Clemson University, \\ Coastal Research and Education Center, Charleston, SC 29414-5333
}

\begin{abstract}
Keinath, A. P. 2002. Survival of Didymella bryoniae in buried watermelon vines in South Carolina. Plant Dis. 86:32-38.

Sections of dead, dried watermelon vines naturally infected with Didymella bryoniae were placed in nylon mesh bags, covered with soil, and placed in a field at 0-, 12.5-, or 25-cm depths in the November or December prior to 1997, 1998, and 1999. The percentage of 1-cm vine segments that yielded $D$. bryoniae and the number of segments retrieved intact declined over time. Vine segments cultured on semiselective medium yielded D. bryoniae for 30, 24, and 21 weeks after placement in 1997, 1998, and 1999, respectively. D. bryoniae was not recovered 32 and 29 weeks after placement at any depth in 1998 and 1999, respectively. A hypocotyl-infection assay using watermelon seedlings was developed to detect $D$. bryoniae conidia produced on recovered vine sections. Using known concentrations of conidia, the percentage of seedlings exhibiting gummy stem blight symptoms increased with the logarithm of the inoculum density. Viable conidia were produced on retrieved vine sections for up to 32 weeks after burial, based on culturing on semiselective agar, but conidia caused disease for only 16 weeks after burial in the hypocotyl-infection assay. Conidia of $D$. bryoniae were recovered 8 weeks longer at $0 \mathrm{~cm}$ than at lower depths in 1999, but not in 1998. Incorporating infested crop residue into soil reduced the number of infective propagules and survival of D. bryoniae.
\end{abstract}

The potential for the cucurbit fungal pathogen Didymella bryoniae (Auersw.) Rehm (anamorph Phoma cucurbitacearum (Fr.:Fr.) Sacc.) to survive in soil in the southern United States was recognized early in the twentieth century. A United States Department of Agriculture Farmer's Bulletin from 1922 recommended crop rotation to prevent gummy stem blight and black rot on watermelon (Citrullus lanatus (Thunb.) Matsum. \& Nikai var. lanatus) (16). In rotation studies previously conducted in South Carolina, gummy stem blight developed on cucumber grown in microplots that had been infested $\leq 18$ months previously with infected host debris (19). No gummy stem blight was observed on cucumbers planted 24 months after infestation, following noncucurbit crops grown in spring and fall each year. $D$. bryoniae infects only members of the Cucurbitaceae (5); therefore, it was recommended that no cucurbits be planted for 2 years to reduce soilborne inoculum of the pathogen (19).

Only two studies, both conducted in northern climates, have directly examined

Corresponding author: A. P. Keinath

E-mail: tknth@clemson.edu

Technical Contribution No. 4645 of Agriculture and Forestry Research, Clemson University, Clemson, SC. This project was partially supported with funds from Hatch Project SC01628.

Accepted for publication 4 October 2001.

Publication no. D-2001-1120-02R

(C) 2002 The American Phytopathological Society survival of $D$. bryoniae in infected host debris. In Wisconsin, D. bryoniae was recovered by culturing from naturally infected watermelon and squash stems overwintered on the soil surface (5). In this study, new pycnidia formed on overwintered debris in late spring, 6 months after placement in the first year; whereas, in the second year, no pycnidia formed because the debris decayed completely. The authors proposed that the fungus survived as dormant mycelium in infested debris. In the Netherlands, D. bryoniae survived 5 months over winter on the soil surface, even during a 14-day period when temperatures dipped below $0^{\circ} \mathrm{C}$ and reached a minimum of $-9^{\circ} \mathrm{C}(21)$. The pathogen also survived for 10 months in cucumber stems buried in dry, nonsterile soil in a greenhouse and for 18 months in dried, infected cucumber stems not buried. However, infected plant material buried outdoors in nonsterile soil was completely decomposed after 9 months. In both studies, the authors reported that spores within pycnidia and pseudothecia present on plant material when it was buried disappeared before the end of the sampling periods. No studies have been conducted on survival of $D$. bryoniae in the southern United States, where warmer temperatures during the winter may either promote survival, or, conversely, hasten the demise of this foliar pathogen because of greater microbial antagonism on, or more rapid decay of, infected host debris (3).

The objective of this study was to determine the length of time that $D$. bryoniae survives in naturally infected watermelon vines either buried or left on the soil surface. Survival was assessed both by culturing debris on agar media and using a host plant assay to detect infective propagules of the pathogen (6).

\section{MATERIALS AND METHODS}

Survival of $D$. bryoniae in soil. Dead, dried main and secondary watermelon vines, naturally infected with $D$. bryoniae, were collected from experimental plots at the Clemson University Coastal Research and Education Center, Charleston, SC, in October 1996 and November 1997 and 1998. Vines were cut into $5-\mathrm{cm}$ sections, with each section examined to ensure that pycnidia were present. In 1996 and 1997 , all sections with visible pycnidia of $D$. bryoniae were used but, in 1998, only sections with $\geq 60 \%$ of their length covered with pycnidia were used. In 1996, 20 vine sections were placed together in pouches cut from nylon stockings. In 1997 and 1998, sections were placed into 20 separate compartments (one section per compartment) in bags sewn from nylon Nytex 220- $\mu \mathrm{m}$ mesh fabric (Tetko Inc., Kansas City, MO), as described previously $(6,13)$. Soil collected from $0-, 12.5-$, and $25-\mathrm{cm}$ depths was added to the nylon stockings or the compartments to completely cover the vine sections.

Bags were buried horizontally at depths of 12.5 and $25 \mathrm{~cm}$ and left on the soil surface at six replicate sites in one field on 11 November 1996 (1997 experiment) and four replicate sites in one field on 8 December 1997 (1998 experiment) and 8 January 1999 (1999 experiment). The soil was a Yonges loamy fine sand (fine-loamy, mixed, thermic, Typic Albaquults), $\mathrm{pH} 6.1$, 6.3, and 6.0 in the 1997, 1998, and 1999 experiments, respectively. Soil temperatures were measured every $15 \mathrm{~min}$ at each depth and the minimum, maximum, and mean temperatures were recorded for every 24-h period with a CR-10 micrologger (Campbell Scientific, Logan, UT).

At the time of burial, baseline colonization of vine sections by $D$. bryoniae was determined by plating 20 sections in the 1997 experiment and 40 sections in the 1998 and 1999 experiments as described below.

Every 4 to 6 weeks, one bag was retrieved from each depth at each site in the 1997 experiment until all bags had been recovered. In the 1998 and 1999 experiments, bags were retrieved from each depth and site every 8 weeks. When $D$. bryoniae was not recovered from any vine 
segments at any depth at a sampling, one additional sampling was done to confirm the lack of recovery.

D. bryoniae detection. Vine sections were removed from the bags and washed under running tap water for 3 to $5 \mathrm{~min}$ to remove excess soil. Sections were dried in a vacuum chamber (Gast Mfg. Co., Benton Harbor, MI) at $650 \mathrm{~mm} \mathrm{Hg}$ vacuum for 48 $\mathrm{h}$, then placed in an operating laminar flow hood for $24 \mathrm{~h}$ to complete the drying cycle. The specific times used for this gradual drying process were selected during the first three samplings in the 1997 experiment to reduce contaminating bacteria and fungi on the vine sections, while preserving viability of $D$. bryoniae. In a previous study, $D$. bryoniae remained viable for 10 months in air-dried debris (21). In the 1998 and 1999 experiments, 10 of the 20 vine sections from each depth and replication were rehydrated for $10 \mathrm{~min}$ in deionized water and cut into five $1-\mathrm{cm}$ segments, keeping the segments from each vine section together. The sections were rated as intact (i.e., five $1-\mathrm{cm}$ pieces could be cut) or decayed (i.e., four or fewer pieces could be cut). In 1997, 10 of the 20 vine sections from each depth of four randomly chosen replications and all 20 sections from the remaining two replications were used. The remaining 40 vine sections in 1997 were used to develop the host plant assay described below.

In all experiments, vine segments were surface disinfested in $0.5 \%$ sodium hypochlorite solution for $1 \mathrm{~min}$, rinsed with sterile deionized water, and placed on CSR agar (one-quarter-strength potato dextrose agar [QPDA] amended after autoclaving with [per liter] $100 \mathrm{mg}$ of chloramphenicol, $100 \mathrm{mg}$ of streptomycin, and $60.5 \mathrm{mg}$ of metalaxyl [0.25 ml of Ridomil 2E]). Plates were incubated at ambient temperature (22 to $24^{\circ} \mathrm{C}$ ) under a $16-\mathrm{h}$ photoperiod. Segments were examined under $\times 30$ to $\times 50$ magnification after 3 days and again after 1 (1997) or 2 (1998 and 1999) additional days of incubation. D. bryoniae was identified by characteristic hyaline, aerial mycelia, dark green substrate mycelia, and round tan pycnidia with a dark ring of cells around the ostiole $(10,17)$. Pycnidia from selected colonies were excised from the agar and conidia were examined under $\times 200$ to $\times 400$ magnification to confirm identification as D. bryoniae (10). The total number of segments and sections from which colonies of $D$. bryoniae grew were recorded for each depth and replication.

Host plant assay. A host plant assay, based on one used to detect Colletotrichum lindemuthianum in buried bean debris, was adapted to detect levels of $D$. bryoniae capable of causing gummy stem blight (6). A standard curve was developed using known levels of $D$. bryoniae conidia produced on naturally infected watermelon vines and in culture. In the first test, dried, infected watermelon vines were cut into 5$\mathrm{cm}$ lengths, rehydrated in sterile, deionized water for $10 \mathrm{~min}$, and placed on screens over water in closed plastic boxes to provide $100 \%$ relative humidity $(\mathrm{RH})$. In all, 150 sections were incubated for $48 \mathrm{~h}$ at ambient temperature $\left(22\right.$ to $\left.24^{\circ} \mathrm{C}\right)$ under a 16-h photoperiod to induce $D$. bryoniae to produce conidia (2). Ten sections were placed in 250-ml flasks, covered with 10 $\mathrm{ml}$ of sterile deionized water, and shaken on a platform shaker at $250 \mathrm{rpm}$ for $1 \mathrm{~h}$ to dislodge conidia. The liquid was decanted and centrifuged for $2 \mathrm{~min}$ at 4,000 rpm in a tabletop centrifuge (International Equipment Co., Needham Hts., MA) to collect the conidia, which were resuspended in a final volume of $10 \mathrm{ml}$ of sterile deionized water. The concentration of conidia was determined by counting in a hemacytometer. A dilution series was prepared with concentrations approximately equally spaced on a $\log _{10}$ scale, $0,10^{3}, 10^{4.5}, 10^{6}$, and $10^{7}$ conidia/ml. A conidial suspension of $D$. bryoniae isolate $\mathrm{W} 432$, originally obtained from a dried watermelon vine, was used as a positive control. This isolate was grown on QPDA under a 16-h photoperiod at ambient temperature (22 to $24^{\circ} \mathrm{C}$ ) for 3 weeks. Conidia were suspended in $5 \mathrm{ml}$ of sterile distilled water and filtered through four layers of sterile cheesecloth, counted with a hemacytometer, and adjusted to $5 \times 10^{5}$ conidia/ml (equivalent to $10^{5.7}$ ). Because it was not possible to collect enough conidia from vines for the highest concentration $\left(10^{7.5}\right)$, only conidia of isolate W432 produced on QPDA were used in the second test. Concentrations of $0,10^{1.5}, 10^{3}, 10^{4.5}, 10^{6}$, and $10^{7.5}$ conidia/ml were tested.

Watermelon cv. Jubilee II was seeded in 72 -cell flats in $60 \%$ peat $-40 \%$ vermiculite potting mix. Seedlings were wound inoculated, based on a pathogenicity assay used by Chiu and Walker (5). Hypocotyls of 7 to 10-day-old seedlings were injected just below the cotyledons with a 23-gauge needle and syringe that delivered $0.02 \mathrm{ml}$ of conidial suspension per seedling. For each concentration, three replicate flats with 50 seedlings each were inoculated, except that in test one the highest concentration was done only once because not enough conidia were obtained. In addition, hypocotyls of 10 seedlings were injected with sterile deionized water to serve as noninoculated controls for each replication of each concentration. Flats were placed in a complete randomized block in three mist chambers at $95 \%$ relative humidity. RH was maintained with a humidifier placed within each chamber. After 7 to 10 days, the number of seedlings with symptoms of gummy stem blight on the hypocotyls was counted. Hypocotyl sections, $2 \mathrm{~cm}$ long, from diseased seedlings were surface disinfested and plated on CSR agar to confirm the presence of $D$. bryoniae.

At each sampling, including the baseline sample, in the 1998 and 1999 experiments, the 10 vine sections recovered from each replication and depth but not cultured were rehydrated and incubated for $72 \mathrm{~h}$ at $100 \%$ $\mathrm{RH}$ to produce conidia as described above. After centrifugation, the pelleted conidia were resuspended in $3 \mathrm{ml}$ of sterile distilled water. To determine the conidial concentration, 0.1-ml aliquots were spread on four plates of CSR agar. The conidial suspension prepared for each replication and depth was used to inoculate 5010 - to 14-day-old watermelon seedlings as described above. Four additional sets of 50 seedlings were injected with sterile distilled water to serve as noninoculated controls, one for each replicate field site. Inoculated and control seedlings for each replicate field site were placed together in a humidity chamber and incubated at $95 \%$ RH for 7 days. Diseased seedlings were counted after 7 to 10 days and portions of the hypocotyls were surface disinfested and cultured on CSR agar. At the last sampling in the 1999 experiment, a treatment of seedlings inoculated with $D$. bryoniae at $10^{3}$ conidia/ml from 14-dayold QPDA cultures was included as a positive control.

Table 1. Split-plot analysis of variance for isolation of Didymella bryoniae from naturally infected watermelon vine segments that had been buried at depths of $0,12.5$, or $25 \mathrm{~cm}^{\mathrm{a}}$

\begin{tabular}{|c|c|c|c|c|c|c|c|c|c|}
\hline \multirow[b]{2}{*}{ Source } & \multicolumn{3}{|c|}{1997} & \multicolumn{3}{|c|}{1998} & \multicolumn{3}{|c|}{1999} \\
\hline & df & Sum of squares & $\operatorname{Pr}>F$ & df & Sum of squares & $P r>F$ & df & Sum of squares & $\operatorname{Pr}>F$ \\
\hline Depth & 2 & 0.017 & 0.001 & 2 & 0.001 & 0.34 & 2 & 0.001 & 0.37 \\
\hline Depth (site) ${ }^{\mathrm{b}}$ & 15 & 0.012 & $\ldots$ & 9 & 0.003 & $\ldots$ & 9 & 0.006 & 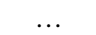 \\
\hline Time & 6 & 0.168 & 0.0001 & 5 & 0.155 & 0.0001 & 4 & 0.320 & 0.0001 \\
\hline Time $\times$ depth & 12 & 0.016 & 0.01 & 10 & 0.005 & 0.67 & 8 & 0.008 & 0.12 \\
\hline Error & 89 & 0.050 & $\ldots$ & 45 & 0.028 & $\ldots$ & 36 & 0.022 & $\ldots$ \\
\hline
\end{tabular}

${ }^{a}$ Percentage of vine segments yielding $D$. bryoniae on semiselective medium (number of positive segments/total number of segments recovered) was transformed with arcsin-square root before analysis.

${ }^{\mathrm{b}}$ Depth (site) was used as the error term for depth. 
Statistical analysis. Analysis of variance was performed using PROC GLM of SAS (version 6.12; SAS Institute, Inc., Cary, NC). In each analysis, data were tested for homogeneity of variance and normality and transformed when necessary. Percentages of segments yielding $D$. bryoniae were transformed with the arcsin-

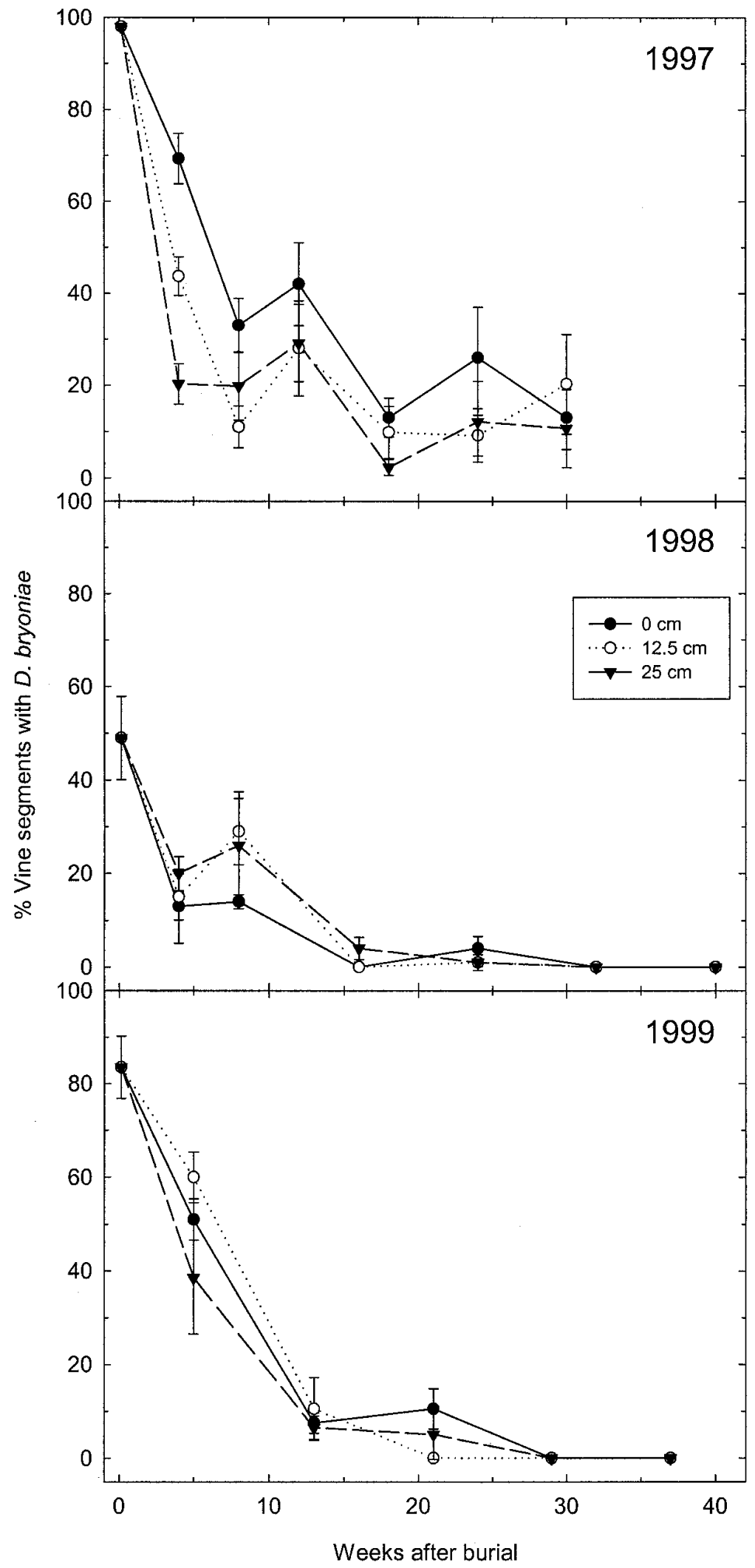

Fig. 1. Growth of Didymella bryoniae from naturally infected, buried watermelon vine segments retrieved over time and cultured on semiselective medium. Each data point is the mean of four to six replications in 1997 and four replications in 1998 and 1999. Error bars show one standard error of the means. square root before a split-plot analysis was done, with site and depth as the whole-plot factors and time as the subplot factor. Percentage of diseased seedlings in the host plant assays, expressed as number of symptomatic seedlings per number inoculated, also was transformed by arcsinsquare root for certain samplings. Estimates of intercepts, slopes (linear coefficients), and quadratic coefficients (when needed) were calculated for the standard curve of the inoculum concentrations used in the host plant assay and the number of conidia produced on recovered sections over time. Fisher's protected least significant differences (LSD) were used to compare depths, Dunnett's $t$ tests were used to compare treatment means to baseline values, preplanned orthogonal linear contrasts were used to compare sampling times, and $t$ tests with least-squares means were used to compare depths and times.

\section{RESULTS}

Survival in soil. In 1997, 1998, and 1999, 98, 48.5 ( \pm 8.9 SE), and 83.5\% ( \pm $6.7)$ of the $1-\mathrm{cm}$ vine segments were colonized by $D$. bryoniae at the time of burial. In 1998 and 1999, but not 1997, segments were buried in soil for 1 day before assaying. There was a highly significant decrease over time in recovery of $D$. bryoniae from buried vine segments in all 3 years (Table 1). D. bryoniae was recovered from segments at one or more depths at all six samplings for 30 weeks after burial in 1997 (Fig. 1). In 1998, the pathogen was recovered at four of six samplings through week 24 , but not at weeks 32 or 40 . In 1999 , the pathogen was recovered at three of five samplings through week 21 , but not at week 29 or 37 . In all 3 years at all recovery times, the percentage of vine segments yielding $D$. bryoniae was significantly lower than the starting percentages (least-squares means $t$ tests, $P=0.001$ in 1997; Dunnett's $t$ tests, $P=0.001$ in 1998 and $P=0.0001$ in 1999).

The decrease in recovery of $D$. bryoniae over time followed a complex pattern in 1997 and 1998 that could not be adequately explained with a linear polynomial model or a nonlinear exponential decay model (Fig. 1). In 1997, there was a significant time-depth interaction (Table 1). Percentage of recovery of $D$. bryoniae was greater at $0 \mathrm{~cm}$ than at 12.5 and $25 \mathrm{~cm}$ at 4 , 8 , and 24 weeks after burial ( $t$ tests, $P \leq$ 0.05 ; Fig. 1). At 18 weeks, percent recovery of $D$. bryoniae was greater at 0 $\mathrm{cm}$ than at $25 \mathrm{~cm}$; at 30 weeks, percent recovery was greater at 12.5 than at $25 \mathrm{~cm}$ $(P<0.01)$. In 1998 and 1999, there were no significant effects of burial depth on recovery from vine segments and no timedepth interactions (Table 1). In 1998, percentage of recovery was greater at 4,8 , and 24 weeks when compared with the mean of subsequent recovery times (orthogonal linear contrasts, $P=0.0004, P=0.0001$, 
and $P=0.03$, respectively), but recovery at 16 weeks was not significantly greater than the mean of 24 and 32 weeks. In 1999, however, percent recovery from vine segments decreased over time in a quadratic manner described by the linear equation $y=9.34-0.579 x+0.009 x^{2}$, where $y=$ square root of percent vine segments colonized and $x=$ weeks after burial $\left(R^{2}=0.95\right)$.

Both the total number of vine sections retrieved from nylon bags and the number of $1-\mathrm{cm}$ segments that could be cut from the sections, based on the lengths of the remaining sections, declined significantly over time in 1998 and 1999, but not in 1997. In both 1998 and 1999, numbers of sections and segments declined quadratically (i.e., at a decreasing rate) over time, starting after 16 weeks of burial in 1998 and 13 weeks in 1999 (Fig. 2). In both years, the number of intact segments appeared to stabilize approximately 30 weeks after burial for all depths except $0 \mathrm{~cm}$ in 1999. In 1999, the number of 1-cm segments retrieved at the $0-\mathrm{cm}$ depth was greater than at the $12.5-$ or $25-\mathrm{cm}$ depth at 21, 29, and 37 weeks after burial (LSD, $P$ $=0.01$; Fig. 2). There was no effect of burial depth on number of remaining sections or segments in 1997 or 1998, although vine sections buried at 12.5 and 25 $\mathrm{cm}$ became less firm over time in 1997.

The highest daily maximum and lowest daily minimum temperatures recorded at 0 $\mathrm{cm}$ were $33.7,37.3$, and $39.9^{\circ} \mathrm{C}$ and -6.2 , -5.6 , and $-4.3^{\circ} \mathrm{C}$ in the 1997,1998 , and 1999 experiments, respectively. Maximum and particularly minimum temperatures at the soil surface $(0 \mathrm{~cm})$ were higher and lower, respectively, than at 12.5 and $25 \mathrm{~cm}$ in all 3 years (data not shown). Daily minimum temperatures were as much as $9^{\circ} \mathrm{C}$ lower at $0 \mathrm{~cm}$ than at $12.5 \mathrm{~cm}$. The yearly mean minimum temperature was 3.8 to $5.7^{\circ} \mathrm{C}$ lower at $0 \mathrm{~cm}$ than at the other two depths. Minimum temperatures were essentially identical at 12.5 and $25 \mathrm{~cm}$, whereas maximum temperatures were similar at these two depths in 1997 and 1998 , but $1.3^{\circ} \mathrm{C}$ higher at $12.5 \mathrm{~cm}$ than at $25 \mathrm{~cm}$ in 1999 . The yearly mean minimum and maximum temperatures across the first 30 weeks were approximately $2{ }^{\circ} \mathrm{C}$ higher at all depths in 1999 than in 1997.

Host plant assay. When known concentrations of conidia of $D$. bryoniae were injected into watermelon seedling hypocotyls, the percentage of seedlings with symptoms of gummy stem blight increased linearly with the $\log$ of the inoculum concentration (Fig. 3). No seedlings exhibited symptoms of gummy stem blight when inoculated with sterile water or the lowest concentration tested, $10^{1.5}$ (equivalent to 32) conidia $/ \mathrm{ml}$. Based on the linear regression equation of $y=-53.9+20.1 x$, where $y=$ percentage of seedlings infected and $x=\log _{10}$ (inoculum concentration) $\left(R^{2}\right.$ $=0.67)$, a minimum concentration of 600 conidia/ml (12 conidia per $0.02-\mathrm{ml}$ aliquot) was required to produce 1 diseased seeding out of 50 ( $2 \%$ seedlings infected). The maximum predicted disease percentage was $97 \%$ at a concentration of $3.2 \times 10^{7}$ conidia $/ \mathrm{ml}$. At $10^{4}$ to $10^{6}$ conidia $/ \mathrm{ml}$, more seedlings became diseased with conidia produced on QPDA than on naturally infected vines, but at $10^{3}$ and $10^{7}$ conidia $/ \mathrm{ml}$, the two sources of conidia did not differ (least-squares means $t$ tests, $P=0.0001$ ). $D$. bryoniae was reisolated from 100 and $90 \%$ (range of 77 to $100 \%$ per replication) of the symptomatic seedlings in tests one and two, respectively.

In 1998, the number of viable conidia produced on 105 -cm-long retrieved vine sections was low for most samplings and did not differ significantly over time or by depth (Fig. 4). Mean number of colonies of $D$. bryoniae recovered on CSR agar between 4 and 32 weeks after burial was equivalent to $0.97 \times 10^{3}$ conidia/ml $( \pm 0.37 \mathrm{SE})$. However, there was a noticeable peak at 8 weeks after burial for all three depths, with a mean across depths of $4.0( \pm 1.6) \times 10^{3}$ conidia $/ \mathrm{ml}$ (Fig. 4). In 1999, the mean number of viable conidia decreased significantly in a quadratic fashion between 5 and 29 weeks after burial $\left(R^{2}=0.99\right.$; Fig. 4). More colonies were obtained from vine sections placed at $0 \mathrm{~cm}$ than from sections that had been buried. The intercept and slope terms were significantly lower for 12.5 and $25 \mathrm{~cm}$ than $0 \mathrm{~cm}$ but did not differ between 12.5 and $25 \mathrm{~cm}$ (single-degree of freedom contrasts, $P \leq 0.002$ ). No colonies were produced 13, 21, and 29 or more weeks after

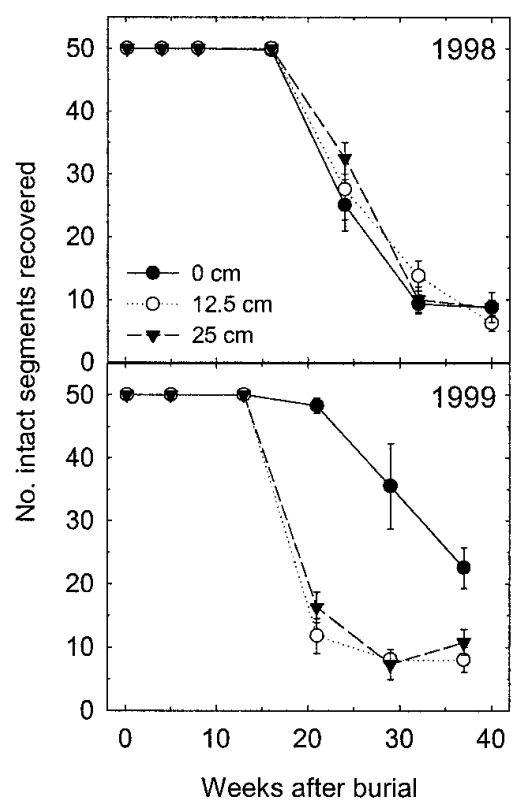

Fig. 2. Decay of buried watermelon vine sections retrieved over a 40-week period, measured as the number of intact, $1-\mathrm{cm}$ segments that could be cut from 105 -cm-long sections. Each data point is the mean of four replications. Error bars show one standard error of the means. burial on vine sections retrieved from depths of $25,12.5$, and $0 \mathrm{~cm}$, respectively (Fig. 4).

In the seedling inoculation tests, 6.5 and $56 \%$ of the watermelon seedling hypocotyls showed symptoms of gummy stem blight in 1998 and 1999, respectively, when inoculated with conidia produced on stems buried for 1 day (baseline; Table 2). Based on the standard curve, the conidial suspensions after 1 day of burial contained $10^{3}$ and $2.9 \times 10^{5}$ conidia $/ \mathrm{ml}$ in 1998 and 1999, respectively. In 1998, watermelon seedlings developed symptoms of gummy stem blight when inoculated with spore suspensions prepared from vine sections retrieved from all three depths at 4,8 , and 16 weeks after burial (Table 2). Two seedlings inoculated with conidial suspensions from $12.5 \mathrm{~cm}$ and one noninoculated control seedling in the same replication also had symptoms of gummy stem blight in the 40-week assay. In 1999, only seedlings inoculated with spore suspensions collected 5 weeks after vine sections had been buried became diseased and yielded $D$. bryoniae on reisolation. Conidial suspensions for the three depths contained a mean of $1.4 \times 10^{3}$ conidia $/ \mathrm{ml}$. This was the only sampling in both experiments in which percentage of diseased seedlings for all depths was significantly greater than the noninoculated control (Fisher's protected LSD, $P=0.05)$. No disease developed on any seedlings inoculated with conidial suspensions prepared from retrieved vine sections at $13,21,29$, or 38 weeks after burial in 1999. The positive control done at 38 weeks had $2 \%( \pm 0.8)$ diseased seedlings and $D$. bryoniae was reisolated. There was no effect of depth of burial on percent diseased seedlings in either year.

\section{DISCUSSION}

The relatively short time period, 7 months, during which $D$. bryoniae could be

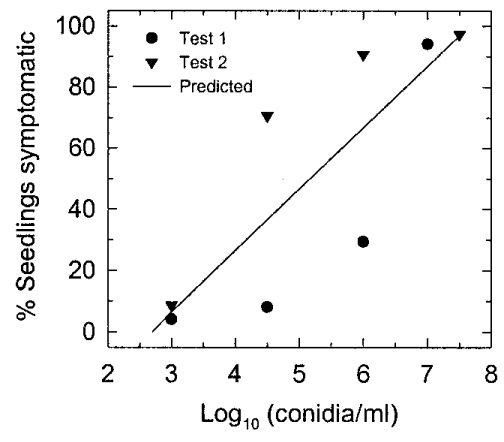

Fig. 3. Relationship between inoculum concentration of Didymella bryoniae and percent watermelon seedlings developing gummy stem blight. Conidia were produced on naturally infected watermelon vine sections in test 1 and on one-quarter-strength potato dextrose agar in test 2 and injected into seedling hypocotyls. $R^{2}$ $=0.67$. Each data point is the mean of three replications, except at $\log 7$, which had only one replication. 
recovered from watermelon debris is similar to that reported in a previous study, in which $D$. bryoniae was not recovered from decayed, buried cucumber stem pieces after 9 months (21). In 1998 and 1999, D. bryoniae was recovered from only 5 to $10 \%$ of vine segments when $100 \%$ of the segments still were intact. At oniae was not recovered at all when 10 to $20 \%$ of the vine segments were intact. Therefore, $D$. bryoniae did not survive the same length of time that host tissue persisted in this study. The decline of D. bryoniae in buried debris is a potential example of natural biological control, in which the antagonistic activity of saprophytic soil microorganisms might eliminate pathogens resident in infected host crop debris (3). the end of the two experiments, D. bry-

Similarly, C. lindemuthianum generally did not survive overwinter in kidney bean pods left on the soil surface in New York State, although pod debris was still retrieved in May of the year following planting (6).

There were few differences among the three burial depths used in this study. The most plausible explanation for this result is that vine sections left on the soil surface were covered with soil inside the nylon mesh bags, just as the buried sections were. Apparently the greater fluctuations in minimum and maximum temperatures at the soil surface than at 12.5 and $25 \mathrm{~cm}$ below the surface had no detrimental effect on survival of $D$. bryoniae. Absolute minimum temperatures in the 3 years of this study were $\geq-6^{\circ} \mathrm{C}$., which $D$. bryoniae can withstand in infested debris (21). In 1998,

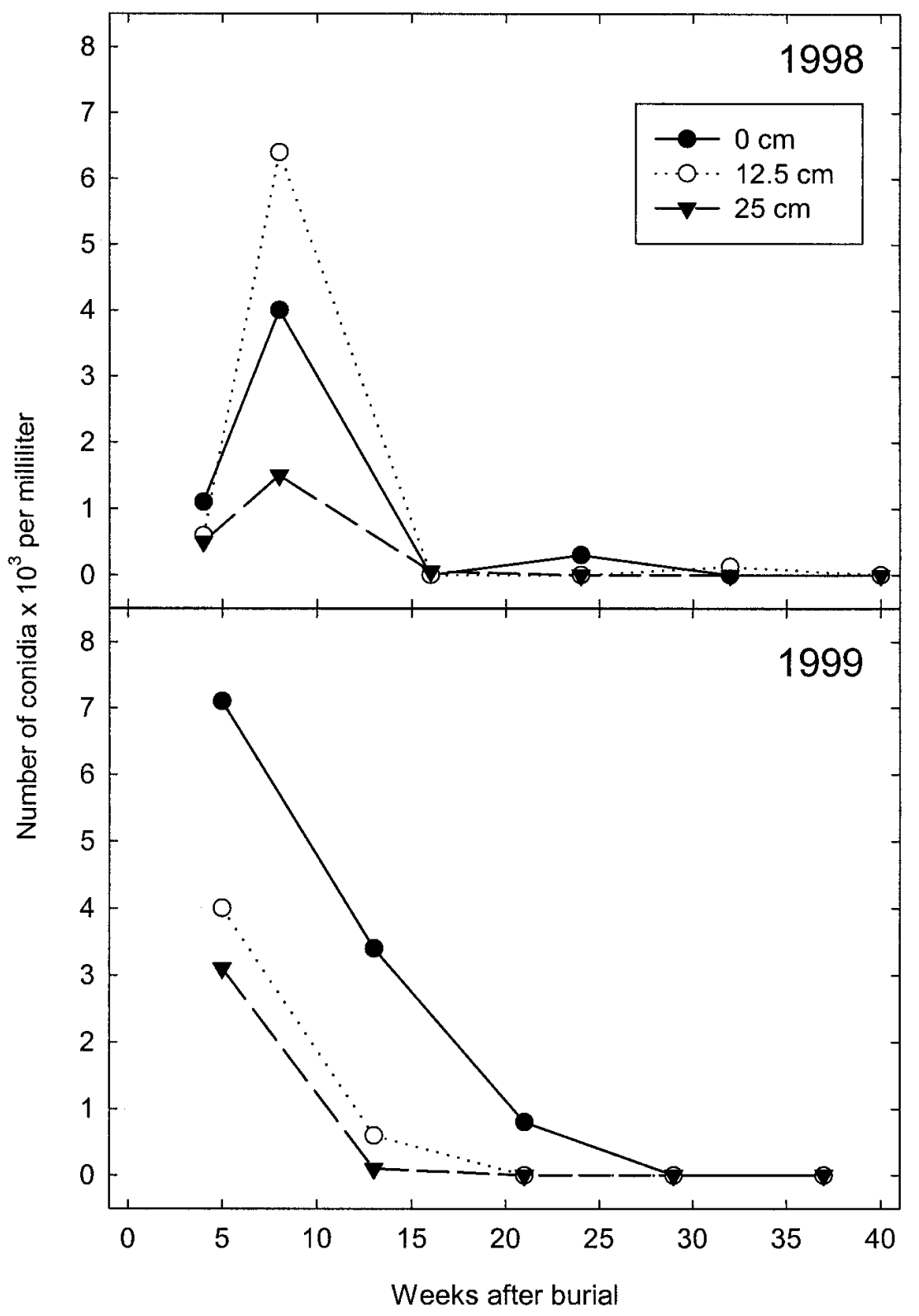

Fig. 4. Number of conidia produced by Didymella bryoniae on 105 -cm-long naturally infected, buried watermelon vine sections retrieved over time. Vine sections were incubated at $100 \%$ relative humidity for $72 \mathrm{~h}$, then washed to dislodge conidia. Conidia were cultured on semiselective medium. Each mean represents four plates from each of four burial sites. there were 12 days when the maximum temperature at $0 \mathrm{~cm}$ reached or exceeded $36^{\circ} \mathrm{C}$., a temperature lethal in vitro to conidia of D. bryoniae (5). However, these elevated temperatures occurred between 24 and 32 weeks after burial, when reisolation from stem segments was already low (Fig. 1 ). When there were differences in recovery of $D$. bryoniae among burial depths (e.g., percent recovery of $D$. bryoniae from vine segments in 1997 and number of conidia produced on retrieved segments in 1999), D. bryoniae persisted longer in debris on the soil surface than in buried debris. In two previous studies, infested cucurbit debris was overwintered on the soil surface but not covered with soil, and D. bryoniae was reisolated 5 to 7 months later $(5,21)$. Population density of Phialophora gregata and persistence of soybean debris also were greater on the soil surface than at $20 \mathrm{~cm}$ of depth (1).

Watermelon vines were chosen as the crop residue to use in this study because a sufficient quantity could be obtained readily from plots of watermelon naturally infected and colonized by $D$. bryoniae. Cucurbit vines exhibit secondary growth, including a perivascular cylinder partially composed of lignin (7). Therefore, vine sections would persist longer in soil than nonlignified portions of watermelon plants, such as leaves or tendrils, but not as long as crowns and stems, which are the thickest tissues. Cankers occur on main stems $(17,18)$; therefore, $D$. bryoniae probably could survive longer in these thicker tissues than on the vine sections examined in this study. This may explain why, in two previous rotation studies, gummy stem blight occurred in cucurbit crops planted 1.5 to 2 years after the previously infected cucurbit crop $(9,19)$. In adjacent fields of watermelon, gummy stem blight severity was significantly greater in the field cropped 2 years previously to melons than in the field that was not previously cropped to melons (9). In microplots, D. bryoniae infected cucumbers planted in soil infested 18 months previously (19). However, a low level of gummy stem blight also was observed in the noninfested microplots. Ascospores of the fungus have been trapped over watermelon fields throughout the year in Florida (18) and in and around cucumber greenhouses in The Netherlands (21); therefore, some of the plants in these two studies may have become infected by airborne inoculum. Nevertheless, the main source of $D$. bryoniae inoculum in these two studies appears to have been infested soil, but the exact survival mechanism of $D$. bryoniae was not determined.

Numerous pycnidia were present on the watermelon vine sections when they were placed in the field; therefore, it was not possible to determine whether the conidia produced on retrieved sections were produced in existing pycnidia or in newly 
4. Brown, M. E., Howard, E. M., and Knight, B. C. 1970. Seed-borne Mycosphaerella melonis on cucumber. Plant Pathol. 19:198.

5. Chiu, W. F., and Walker, J. C. 1949. Physiology and pathogenicity of the cucurbit blackrot fungus. J. Agric. Res. 78:589-615.

6. Dillard, H. R., and Cobb, A. C. 1993. Survival of Colletotrichum lindemuthianum in bean debris in New York state. Plant Dis. 77:12331238.

7. Esau, K. 1977. Anatomy of Seed Plants, 2nd ed. John Wiley \& Sons, New York.

8. Keinath, A. P. 1996. Soil amendment with cabbage residues and crop rotation to reduce gummy stem blight and increase growth and yield of watermelon. Plant Dis. 80:564-570.

9. Keinath, A. P., DuBose, V. B., May, W. H. III, and Latin, R. X. 1998. Comparison of seven fungicide intervals to control gummy stem blight in a fall watermelon crop. Fungic. Nematic. Tests 53:268.

10. Keinath, A. P., Farnham, M. W., and Zitter, T. A. 1995. Morphological, pathological, and genetic differentiation of Didymella bryoniae and Phoma spp. isolated from cucurbits. Phytopathology 85:364-369.

11. Koike, S. T. 1997. First report of gummy stem blight, caused by Didymella bryoniae, on watermelon transplants in California. Plant Dis. $81: 1331$.

12. Lee, D.-H., Mathur, S. B., and Neergaard, P. 1984. Detection and location of seed-borne inoculum of Didymella bryoniae and its transmission in seedlings of cucumber and pumpkin. Phytopathol. Z. 109:301-308.

13. Lumsden, R. D. 1981. A nylon fabric technique for studying the ecology of Pythium aphanidermatum and other fungi in soil. Phytopathology 71:282-285.

14. Navas-Cortes, J. A., Trapero-Casas, A., and Jimenez-Diaz, R. M. 1998. Phenology of Didymella rabiei development on chickpea debris under field conditions in Spain. Phytopathology 88:983-991.

15. Ntahimpera, N., Dillard, H. R., Cobb, A. C., and Seem, R. C. 1997. Influence of tillage practices on anthracnose development and distribution in dry bean fields. Plant Dis.
81:71-76.

16. Orton, W., A. and Meier, F. C. 1922. Diseases of watermelons. U. S. Dep. Agric. Farmers Bull. 1277.

17. Punithalingam, E., and Holliday, P. 1972. Didymella bryoniae. CMI (Commonw. Mycol. Inst.) Descr. Pathog. Fungi Bact. No. 332.

18. Schenck, N. C. 1968. Epidemiology of gummy stem blight (Mycosphaerella citrullina) on watermelon: Ascospore incidence and disease development. Phytopathology 58: 1420-1422.

19. Sitterly, W. R. 1969. Effect of crop rotation on cucumber gummy stem blight. Plant Dis. Rep. 53:417-419.

20. Trapero-Casas, A., and Kaiser, W. J. 1992. Development of Didymella rabiei, the teleomorph of Ascochyta rabiei, on chickpea straw. Phytopathology 82:1261-1266.

21. van Steekelenburg, N. A. M. 1983. Epidemiological aspects of Didymella bryoniae, the cause of stem and fruit rot of cucumber. Neth. J. Plant Pathol. 89:75-86. 